\title{
Towards More Sustainable Diets: Investigating Consumer Motivations towards the Purchase of Green Food
}

\author{
Min-Yen Chang ${ }^{1}$, Lin-Jyun Huang ${ }^{2}$ and Han-Shen Chen ${ }^{2,3, *(D)}$ \\ 1 Department of Accounting, Jiaxing University, Jiaxing 314001, China; zmy000223@gmail.com \\ 2 Department of Health Industry Technology Management, Chung Shan Medical University, \\ Taichung City 40201, Taiwan; jim89893768@gmail.com \\ 3 Department of Medical Management, Chung Shan Medical University Hospital, No. 110, Sec. 1, \\ Jianguo N. Rd., Taichung City 40201, Taiwan \\ * Correspondence: allen975@csmu.edu.tw; Tel.: +886-4-2473-0022 (ext. 12225)
}

Citation: Chang, M.-Y.; Huang, L.-J.;

Chen, H.-S. Towards More

Sustainable Diets: Investigating

Consumer Motivations towards the

Purchase of Green Food.

Sustainability 2021, 13, 12288. https://

doi.org/10.3390/su132112288

Academic Editor: Markus Keck

Received: 5 October 2021

Accepted: 5 November 2021

Published: 7 November 2021

Publisher's Note: MDPI stays neutral with regard to jurisdictional claims in published maps and institutional affiliations.

Copyright: (c) 2021 by the authors. Licensee MDPI, Basel, Switzerland. This article is an open access article distributed under the terms and conditions of the Creative Commons Attribution (CC BY) license (https:// creativecommons.org/licenses/by/ $4.0 /)$.

\begin{abstract}
The concept of green consumption has become an environmental topic that draws worldwide attention. In order to mitigate environmental damage, it is imperative to increase the recyclability of the food system, and therefore, novel, sustainable, and produced foods need to be supplied to the food system. Among such foods, precooked plant-based foods (PPBFs), which feature health, convenience, and functionality, have become a new trend of the food culture. This study uses the value-attitude-behavior (VAB) model as the theoretical framework and incorporates research variables, such as "environmental concern", "time pressure", and "cooking habit", so as to discuss consumers' behavioral intention toward PPBFs. The research results reveal the following: (1) consumers' health value and interest in PPBFs will significantly affect their behavioral intention; (2) there is a significant relationship between environmental concern and behavioral intention; and (3) time pressure and cooking habits indicate an insignificant relationship with behavioral intention.
\end{abstract}

Keywords: consumer behavior; food choice motivations; precooked plant-based foods (PPBFs); novel and healthier products; green food

\section{Introduction}

Owing to rising health awareness worldwide, healthy dieting has drawn increased attention [1,2]. According to the survey data of the Global Wellness Institute (GWI) (2018) [3], the economic scale of the global health industry reached USD 4.5 trillion, with an annual growth rate of $6.4 \%$ from 2015 to 2017 . In the 2018 report of GWI on Food and Beverage Trend, the market survey firm, Mintel, stated that plant-based food will become a trend of the catering industry. According to the survey jointly conducted by the British market survey firm YouGov and the American supermarket Whole Foods Market [4], 80\% of millennial consumers prioritize health when selecting foods; they try to include plant-based foods as part of their daily diet. The study conducted by Hanson and Yun [5] highlighted that the change in consumers' diet preference has led food producers to start producing new healthy foods, such as PPBFs. The so-called PPBFs are made of $100 \%$ vegetarian components; they can provide convenience, save cooking time, and replace traditional food. Moreover, they contain relatively low contents of calorie, sodium, and processed cereal; besides being convenient, they are also nutritious and beneficial to health [6]. For example, frozen vegetables and fruits are produced by using cryopreservation technology to preserve their nutrition, so that there is no additional requirement of cleaning them again and can be directly consumed. These include food items such as Nature's Touch frozen avocado and Earthbound Farm's organic frozen berry set with three varieties of berries sold at Costco; bean products and canned vegetables labeled as salt-reduced or salt-free can lower the intake of sodium (Cirio's canned chickpeas and Carrefour's canned peas and carrots); and plant-based burgers or steak (Vveat's frozen veggie burger steak sold 
at Costco). Considering that only a handful of existing studies have conducted research on PPBFs-related consumer behaviors [6,7], the research motivation of this study is to fill this gap.

The value-attitude-behavior (VAB) model has been widely used in the research of social psychology to discuss consumers' behavioral model [8]. This model consists of three basic constructs: value, attitude, and behavior. The basic concept of value is the criteria that guide people's action; it is relatively subjective, and it is formed through consumers' social and psychological development. The formation of value can change dieting habits and behaviors [9]. Attitude is the feeling of individuals when they engage in specific behaviors, or their positive or negative opinions toward specific behaviors [10]; attitudes exert an impact on individual behaviors [11]. Tudoran, Olsen, and Dopico [12] suggested that value will influence consumer behaviors through attitude. Cheung and To [13] utilized the VAB model to discuss consumer behaviors when selecting plant-based foods; their study highlighted that information disclosure is a key factor for consumers when choosing to purchase plant-based foods. Kim et al. [14] applied the VAB model to discuss consumer behaviors to dine in vegetarian restaurants. Since no study has used the VAB model to discuss the behavioral intention of consumers toward PPBFs, this study attempts to fill this gap in the literature.

With increasing environmental awareness, changes in consumption behaviors have been generated, and individuals' responsibility for environmental protection and consumption behaviors of green products have drawn increased attention [15]. According to one study, when consumers buy foods, they not only consider the nutritional content, the place of origin, and the identification certification, but also the environmental information of foods [16]. The environmental concern of consumers exerts a significant impact on the consumption behaviors of plant-based diets [17]. Therefore, this study includes environmental concern as one of the research variables. Modern lifestyle has led to increasingly tight schedules, prompting individuals to adopt unhealthy life habits and dieting methods, thereby causing malnutrition issues [5]. PPBFs have emerged to fulfill the requirements of convenience and health [18]. Contini, Boncinelli, Gerini, Scozzafava, and Casini [19] highlighted that time pressure on consumers exerts a significant impact on the purchase of PPBFs. Therefore, this study also includes time pressure as one of the research variables. For regular families, meal preparation is a time and energy-consuming process, from ingredient purchase to menu planning to cooking methods to dish washing at the end [20]. This drives many consumers to seek more convenient food choices [5]. Caraher, Dixon, Lang, and Carr-Hill [21] highlighted that consumers who are less accustomed to cooking are more likely to choose highly convenient foods, such as instant foods [22]. Therefore, this study further includes cooking habits as one of the research variables.

Based on the above research background and motivation, this study centers on the VAB model and incorporates three more research constructs (i.e., environmental concern, time pressure, and cooking habits) to discuss consumers' behavioral intention toward PPBFs. It is hoped that the present research findings will help instant food businesses identify key factors influencing consumers' purchases of PPBFs, allowing them to develop effective marketing strategies and expand their business opportunities.

\section{Materials and Methods}

\subsection{The Relationship between Health Value and Interest in PPBFs}

Tudoran, Olsen, and Dopico [12] believe that health value refers to how individuals view their health status, and the health value of consumers has a correlation with product functions and purchase intention. Tromp et al. (2005) [23] highlighted that the higher the health value of consumers, the more likely they are to make healthy choices. Jun, Kang, and Arendt [24] argued that due to different health values, individuals conduct different behaviors to improve health, but the values will positively affect healthy behaviors and attitude toward healthy products, thereby generating interest [25]. Choe and Kim [26] highlighted that the health value of consumers affects their attitude and behavioral inten- 
tion toward local foods. Shin et al. [17] highlighted that for consumers who dine in green restaurants, their eco-friendly attitude will influence their choice of plant-based dieting. Based on the above, this study puts forth Hypothesis 1 :

Hypothesis 1 (H1). The health value will positively affect consumers' interest in PPBFs.

\subsection{The Relationship between Interest in PPBFs and Behavioral Intention}

Behavioral intention is defined as a strong endogenous stimulation, and it is often considered as the cause of behavior [27]. Blackwell, Miniard, and Engle [28] classified consumers' behavioral intention into six constructs, namely, purchase intention, repurchase intention, spend intention, search intention, and consumption intention. Anderson and Srinivasan [29] held the view that when consumers have a high perceived value for products or services, a positive behavioral intention will be generated, e.g., repurchase intention, word-of-mouth promotion, and willingness to recommend to others.

Tudoran, Scholderer, and Brunsø [30] classified the measurement of behavioral intention into three types: (1) intent to repurchase, that is whether the customer is willing to purchase the product or service again in the future; (2) primary behavior, which mainly measures customer loyalty, e.g., the most recent time of purchase, purchase frequency, and purchase quantity; (3) secondary behavior, including recommendation, support, and word-of-mouth by customers. Kock, Josiassen, and Assaf [31] classified the measurement of behavioral intentions into the following: (1) visit or revisit, referring to whether the customer pays a visit on-site or revisits the site; (2) spend or repurchase intention, referring to whether the customer purchases the product or purchases the product again; (3) word-of-mouth recommendations, referring to whether the customer offers positive or negative word-of-mouth recommendations for the product; and (4) feedback to service, referring to whether the customer offers positive or negative feedback to the service. This study will discuss consumers' behavioral intention toward PPBFs. In terms of the measurement constructs of behavioral intention, this study adopts the constructs developed by Tudoran, Scholderer, and Brunsø [30], namely, intent to repurchase, primary behavior, and secondary behavior, so as to understand consumers' behavioral intention when consuming PPBFs.

The study by Zandstra, De Graaf, and Van Staveren [32] highlighted that consumers' interest in healthy foods will affect their intention to purchase vegetables and fruits, indicating that consumers will pay attention to their own health [33]. Roininen [34] demonstrated that consumers believe that healthy foods are beneficial to their health, and therefore, they feel less guilty when eating healthy foods compared to regular foods, thereby increasing their interest in healthy foods. Tudoran, Scholderer, and Brunsø [30] suggested that the more the consumers value health, the more likely they will choose healthy foods. Based on the above, this study develops Hypothesis 2:

Hypothesis 2 (H2). Consumers' interest in PPBFs will positively affect their behavioral intention.

\subsection{The Relationship between Environmental Concern and Behavioral Intention}

With the changes in consumers' attitude toward environmental issues, environmental concern has become one of the determinants for predicting consumers' environmentfriendly behaviors [17]. De Groot and Steg [35] highlighted that consumers' environmental concern will exert an impact on their intention to purchase green products, and it is an important reference factor for evaluating food quality [36]. Hansla, Gamble, Juliusson, and Gärling [37] stated that the measurement constructs of environmental concern can be classified into: (1) environmental concern for oneself (ECself), which indicates the value generated by considering environmental changes from the perspective of consumers themselves; (2) environmental concern for others (EChum), which means the value generated by considering environmental changes from the perspective of others; (3) environmental 
concern for the biosphere (ECbio), which refers to the value generated by considering environmental changes from the perspective of nonhuman subjects.

Helm, Pollitt, Barnett, Curran, and Craig [38] classified the measurement constructs of environmental concern into the following: (1) the egoistic type, which is the concern for our own health, life, and well-being; (2) the social-altruistic type, which is the concern for the future generations, communities, and others; and (3) the biospheric type, which is the concern for the natural environment or specific plants and animals. The study conducted by Skogen et al. [39] highlighted the measurement constructs of environmental concern into the following: (1) ecocentrism, meaning to use an ecosystem-centered approach in discussing environmental issues; (2) anthropocentrism, meaning to use a human-centered approach in discussing environmental issues; (3) dominance, meaning to use a dominant class-centered approach in discussing environmental issues; (4) altruism, meaning to use another people-centered approach in discussing environmental issues.

Tran, Yamamoto, and Sato [40] classified the measurement constructs of environmental concern into the following: (1) personal norms, referring to the individual behaviors that are subject to the causal effect of moral obligations; and (2) altruistic behavior, referring to the perception of the impact of individual behaviors on others. Freire, Quevedo-Silva, Frederico, Vils, and Braga Junior [41] highlighted that the measurement constructs of environmental concern can be classified into the following: (1) concern or interest, which refers to the value consisting of concern or interest toward environmental topics; (2) behavioral intention, which consists of behaviors in the past, present, and in the future; and (3) understand the impact, the degree of understanding of the effect of one's own behavior on the environment.

Based on the research findings, this study will refer to the study of Hansla, Gamble, Juliusson, and Gärling [37] and utilize the three constructs, ECself, EChum, and ECbio, for environmental concern, to understand whether consumers can consider the perspectives of themselves, others, and nonhuman subjects to study the impact on environment when it comes to the consumption of PPBFs.

The study conducted by Lee, Hwang, Kim, and Cho [42] highlighted that consumers' environmental concern will affect their purchase intention for 3D-printed foods. Nilsson et al. [43] believed that consumer behaviors are affected by environmental concern. D'Amico et al. [44] manifested that the purpose of purchasing plant-based food by consumers is affected by environmental concern. The study by Arisal and Atalar [45] showed that environmental concern will affect individual purchase intention. Pienaar, Lew, and Wallmo [46] also demonstrated that environmental concern is an indicator for predicting green purchase behaviors. Based on the above, it can be found that environmental concern is correlated with behavioral intention. Therefore, this study puts forth Hypothesis 3:

Hypothesis 3 (H3). Consumers' environmental concern for PPBFs will positively affect their behavioral intention.

\subsection{The Relationship between Time Pressure and Behavioral Intention}

Time pressure refers to how people solve problems or make the best decision amidst tight schedules [47]. Time pressure is a subjective feeling. When decision makers feel that they do not have enough time to complete their work, and when they believe the available time is more limited than the time to be spent on carrying out a task, they will develop such a feeling [48]. Under time pressure, decision making will increase the psychological burden [49] as well as anxiety and negative emotion of the decision maker, leading to a risk-aversion tendency [50].

Kaplan, Wanshula, and Zanna [51] highlighted that under the limitation of time pressure, consumers will simplify information collection. For example, when under time pressure, consumers prefer to choose (1) high-quality brands; (2) high-priced brands; and (3) characteristic products. Dhar and Nowlis [52] highlighted that when faced with 
time pressure, the response measures of consumers can be classified into three types: (1) accelerate, which means that consumers will speed up the search and processing of information under time pressure; (2) filter, which means that consumers will focus on relatively important considerations, as well as pay extra attention to negative information; and (3) alter, which means that consumers will change their means of collecting information and adopt a simpler evaluation approach.

Based on the above, this study refers to the study of Dhar and Nowlis [52] and adopts the three measurement constructs, namely, accelerate, filter, and alter, to measure time pressure and to understand whether consumers think that using PPBFs makes their life more convenient and comfortable and reduces their time pressure for meal preparation.

Dhar and Nowlis [52] suggested that consumers' purchase tendency is related to different degrees of time pressure when making the decision. Consumers will define the economic value of time based on time allocation method; moreover, the value of time will be affected by the perceived time pressure [53]. Etkin, Evangelidis, and Aaker [54] highlighted that when time is pressed, consumers are prone to economic cost decision making, which is to pay extra economic costs to purchase time-consuming products. When time pressure increases, consumers will consider their own time to be more valuable, thereby leading them to purchase instant foods [55]. Therefore, based on the above literature, this study develops the following hypothesis:

Hypothesis 4 (H4). Consumers' time pressure related to PPBFs will positively affect their behavioral intention.

\subsection{The Relationship between Cooking Habit and Behavioral Intention}

Pettinger et al. [56] highlighted that cooking habit will vary because of cultural differences, climate conditions, and growth environments [57]. Caraher, Dixon, Lang, and CarrHill [21] demonstrated that cooking habit affects the direction of food choices made by people, and cooking daily meals and following healthy diet are two of the factors affecting people to make sensible decisions that benefit their health. Lang [58] classified cooking habit into five measurement constructs: (1) cooking time; (2) the relaxed emotion cooking brings to people; (3) the happy emotion cooking brings to people; (4) the creativity cooking brings to people; and (5) having a positive attitude toward cooking activities. Sheth, Newman, and Gross [59] classified cooking habit into five constructs, namely, functional value, emotional value, comprehension value, scenario value, and social value. This study adopts the constructs developed by Lang [58] to understand whether consumers think that PPBFs make their life more convenient and comfortable, and behaviors that facilitate the cooking activities of consumers.

The study conducted by Jo, Lee, and Choe [60] revealed that individuals and families who are less accustomed to cooking can purchase takeaway foods so as to reduce time and workload in the process of meal preparation at home. Contini et al. [6] held that the cooking habit of individuals and families will affect purchase intention toward instant food, and suggested that individuals and families who are less accustomed to cooking will seek more convenient dieting choices (Contini et al., 2018) [19]. Based on the above, this study puts forth Hypothesis 5:

Hypothesis 5 (H5). Consumers' cooking habit related to PPBFs will negatively affect their behavioral intention.

\section{Methods}

\subsection{Conceptual Model}

This study keeps the theoretical framework of the VAB model, and incorporates environmental concern, time pressure, and cooking habit into the measurement, so as to further discuss consumers' behavioral intention toward PPBFs. The research framework is illustrated in Figure 1. 


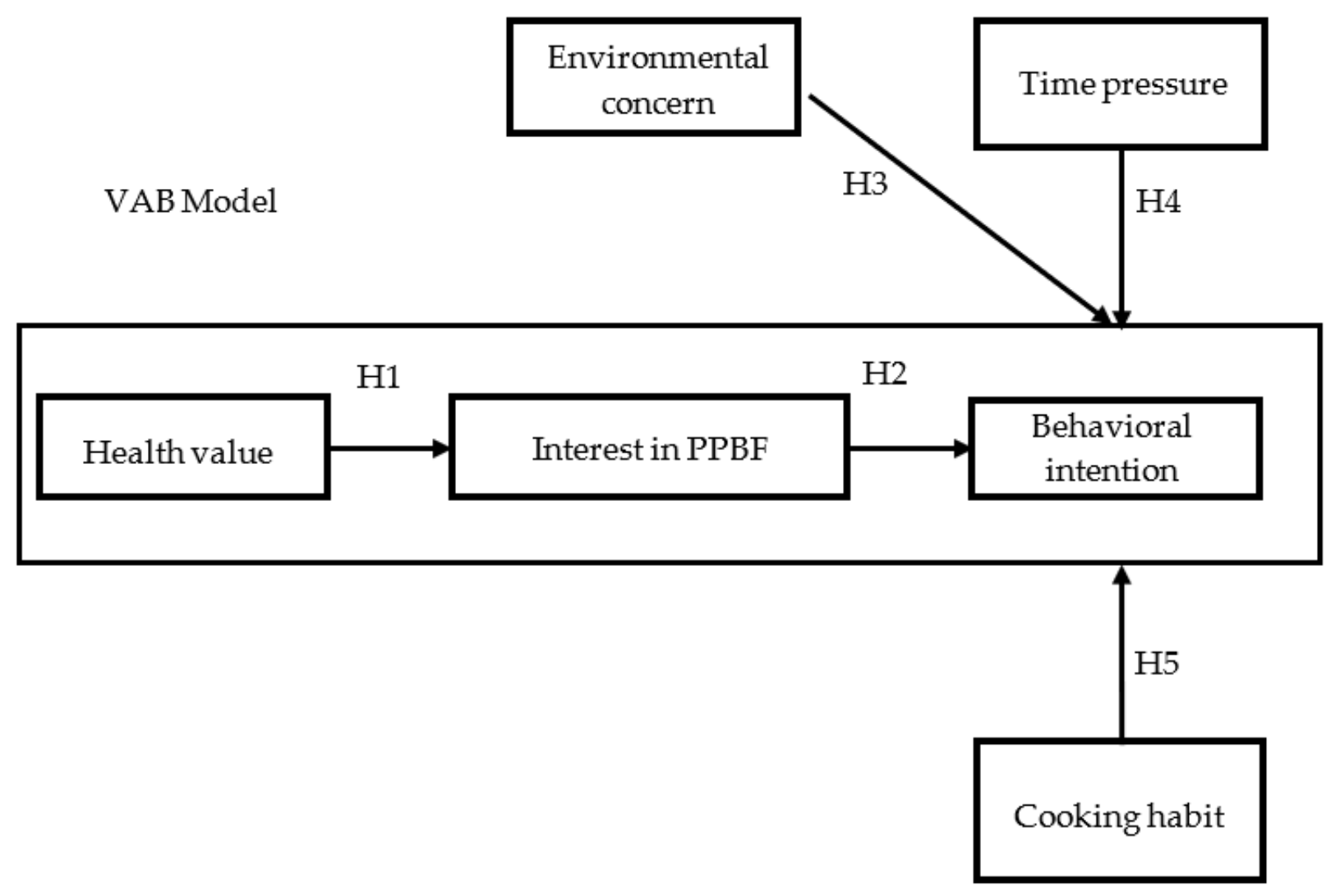

Figure 1. Conceptual model.

\subsection{Measurement Instrument and Data Collection}

The questionnaire contains seven parts. The first three parts are scales for value, attitude, and behavior. The health value refers to the study by Lee, Hwang, Kim, and Cho [42] and includes three items. The interest in PPBFs refers to the study by Lee, Hwang, Kim, and Cho [42] and includes three items. The behavioral intention refers to the study by Tudoran, Scholderer, and Brunsø [30] and includes nine items. The fourth part of the study is the environmental concern scale with nine items, and it refers to the study by Hansla, Gamble, Juliusson, and Gärling [37]. The fifth part is the time pressure scale with nine items, and it refers to the study by Dhar and Nowlis [52]. The sixth part is cooking habit scale with six items, and it refers to the study of Lang (2020) [58]. In this study, the Cronbach's $\alpha$ values of all constructs reach above 0.70 , indicating that the measurement tools of this study are reasonable. The above-mentioned six parts adopt the seven-point Likert scale, asking the respondents to select from "strongly disagree (1)" to "strongly agree (7)." The seventh part contains the basic information of respondents, including gender, age, education level, and average monthly income.

Before issuing the formal questionnaires, this study conducted an online pretest questionnaire, hoping to improve the reliability of the scales with the answers of online respondents. A total of 50 valid samples were recovered for the pretest. This study used a reliability measurement to examine whether the test results were stable and consistent.

In this study, purposive sampling was used to investigate the local residents who live in Taichung city, Taiwan. The study is based on the following criteria: (1) customers who have visited to consume one or more PPBF from any Hypermarket, and (2) addressing customers at Costco and PX Mart. A one-on-one interview method was adopted to clarify any ambiguities in the questionnaire and help respondents fill out the questionnaire seamlessly online (SurveyCake Forms), and they were given approximately $10 \mathrm{~min}$ to fill it out. If potential interviewees had not tried PPBF, the interview was discontinued. The investigation period was from July 2021 to August 2021. This study distributed a total 
of 450 copies of formal questionnaires. After filtering out the unanswered and incomplete responses, the study acquired 391 copies of valid questionnaires, with a valid recovery rate of $87.1 \%$.

With regards to the statistical results of respondents' socioeconomic characteristics, in terms of gender, males account for $44.9 \%$ and females account for $55.1 \%$. In terms of age, the age group of 51-60 years old constitutes the highest proportion (accounting for 24.5\%), followed by the age group of 41-50 years old (accounting for 21.8\%). In terms of education level, the group of junior college and college has the highest proportion (accounting for $52.9 \%$ ), followed by high (vocational) school (accounting for $22.8 \%$ ). In terms of personal monthly income, the group with an average monthly income of NTD 40,001-60,000(USD 1440-2160/EUR 1236-1854) has the highest proportion (accounting for 42.9\%), followed by the group with an average monthly income of NTD 20,001-40,000(USD 720-1440/EUR 618-1236).

\subsection{Statistical Analysis}

The theoretical framework was analyzed using Statistical Package for Social Science (SPSS) and Analysis of Moment Structure (AMOS) version 20. Two structural equation modeling (SEM) study models were investigated in a study. The two models, namely a measurement model and a structural model, were used to test for validity and reliability, and to test for model fit and hypothesis, respectively.

\section{Results}

\subsection{Measurement Model: Reliability and Validity}

The reliability and validity analysis results of the constructs are listed in Table 1 . In terms of convergent validity, if the factor loading value of construct is above 0.5 , then it indicates that the item has convergent validity [61]. Jöreskog and Sörbom [62] suggested that the construct reliability (CR) should fulfill the threshold requirement of 0.6 or above. In this study, the factor loading values of all constructs are above the standard of 0.5 , and all CR values fall between 0.62 and 0.92 , significantly higher than the minimum threshold of 0.6. This indicates internal consistency among all variables. In terms of the average variance extracted (AVE), although the cooking habit (with an AVE value of 0.45) fails to meet the threshold of 0.5 or above, all AVE values of the remaining constructs of this study are above 0.5 , indicating that except for the cooking habit construct, all constructs of this study have convergent validity. Overall, with regard to the internal quality of the measurement model, the health value, interest in PPBFs, environmental concern, and behavioral intention meet the ideal quality level. Means, standard deviations, and correlations among the constructs are presented in Table 2 .

Table 1. Results of the factor loading, reliability, and validity.

\begin{tabular}{|c|c|c|c|c|c|}
\hline Construct & Standard Factor Loading & $t$-Value & $\begin{array}{c}\text { Reliability of } \\
\text { Specific Items-R }\end{array}$ & CR & AVE \\
\hline Health value & & & & 0.90 & 0.76 \\
\hline Health value 1 & 0.91 & $11.19^{* * *}$ & 0.83 & & \\
\hline Health value 2 & 0.81 & $13.72 * * *$ & 0.66 & & \\
\hline Health value 3 & 0.89 & $12.34^{* * *}$ & 0.79 & & \\
\hline Interest in PPBFs & & & & 0.88 & 0.72 \\
\hline Interest in PPBFs 1 & 0.89 & $11.99 * * *$ & 0.78 & & \\
\hline Interest in PPBFs 2 & 0.78 & $13.92 * * *$ & 0.60 & & \\
\hline Interest in PPBFs 3 & 0.87 & $13.54 * * *$ & 0.76 & & \\
\hline
\end{tabular}


Table 1. Cont.

\begin{tabular}{|c|c|c|c|c|c|}
\hline Construct & Standard Factor Loading & $t$-Value & $\begin{array}{c}\text { Reliability of } \\
\text { Specific Items-R }\end{array}$ & CR & AVE \\
\hline $\begin{array}{l}\text { Environmental } \\
\text { concern }\end{array}$ & & & & 0.87 & 0.69 \\
\hline ECself & 0.89 & $10.80 * * *$ & 0.80 & & \\
\hline EChum & 0.92 & $9.85^{* * *}$ & 0.84 & & \\
\hline ECbio & 0.65 & $13.46^{* * *}$ & 0.42 & & \\
\hline Time pressure & & & & 0.86 & 0.70 \\
\hline Accelerate & 0.88 & $10.81^{* * *}$ & 0.77 & & \\
\hline Filter & 0.90 & $10.31^{* * *}$ & 0.80 & & \\
\hline Alter & 0.65 & $14.13^{* * *}$ & 0.43 & & \\
\hline Cooking habit & & & & 0.62 & 0.45 \\
\hline Time & 0.57 & $13.09^{* * *}$ & 0.33 & & \\
\hline Creativity & 0.76 & $9.45^{* * *}$ & 0.59 & & \\
\hline $\begin{array}{l}\text { Behavioral } \\
\text { intention }\end{array}$ & & & & 0.92 & 0.79 \\
\hline $\begin{array}{l}\text { Intent to } \\
\text { repurchase }\end{array}$ & 0.88 & $9.83^{* * *}$ & 0.77 & & \\
\hline Primary behavior & 0.87 & $10.58^{* * *}$ & 0.76 & & \\
\hline $\begin{array}{l}\text { Secondary } \\
\text { behavior }\end{array}$ & 0.92 & $7.70^{* * *}$ & 0.85 & & \\
\hline
\end{tabular}

Note: ${ }^{* * *} p<0.001$.

Table 2. Means, standard deviations, and correlations of constructs.

\begin{tabular}{cccccccc}
\hline Construct & Mean & S.D. & $\mathbf{1}$ & $\mathbf{2}$ & $\mathbf{3}$ & $\mathbf{4}$ & $\mathbf{5}$ \\
\hline 1. Health value & 4.87 & 1.24 & 1.00 & & & & \\
2. Interest in PPBFs & 4.87 & 1.23 & $0.98^{* *}$ & 1.00 & & & \\
3. Environmental concern & 4.98 & 1.16 & $0.82^{* *}$ & $0.80^{* *}$ & 1.00 & & \\
4. Time pressure & 4.98 & 1.16 & $0.80^{* *}$ & $0.80^{* *}$ & $0.99^{* *}$ & 1.00 & \\
5. Cooking habit & 5.03 & 1.05 & $0.69^{* *}$ & $0.68^{* *}$ & $0.88^{* *}$ & $0.88^{* *}$ & 1.00 \\
6. Behavioral intention & 4.68 & 1.27 & $0.76^{* *}$ & $0.76^{* *}$ & $0.71^{* *}$ & $0.70^{* *}$ & $0.61^{* *}$ \\
\hline
\end{tabular}

Note: ${ }^{* *} p<0.05$.

\subsection{Structural Model: Goodness-of-Fit Statistics and Hypothesis Testing}

The analysis started with a confirmatory factor analysis (CFA) using AMOS 20.0. After an initial CFA analysis, the revised model shows an appropriate level of model fit as seen in Table $3\left(\chi^{2} / \mathrm{df}=1.304, \mathrm{RMSEA}=0.030, \mathrm{GFI}=0.942, \mathrm{NFI}=0.960, \mathrm{AGFI}=0.918, \mathrm{CFI}=0.990\right.$, $\mathrm{PNFI}=0.643, \mathrm{RMR}=0.047$ ). All values for composite reliability, which ranged from 0.792 to 0.916 , clearly exceeded the minimum threshold of 0.60 . This result supported internal consistency among the items for each construct. In addition, all AVE values in the present study were greater than 0.50 , thus supporting convergent validity. Finally, the degree of discriminant validity was acceptable and the AVE value for each study variable clearly exceeded the squared value for its correlations with other study variables [63].

Table 3. Result of the fit indicators of the evaluation model.

\begin{tabular}{cccc}
\hline Fit Index & Ideal Value & Result & Conclusion \\
\hline$\chi 2 / \mathrm{df}$ & $<3$ & 1.304 & Acceptable \\
GFI & $>0.9$ (good fit) & 0.942 & Acceptable \\
AGFI & $>0.9$ (good fit) & 0.918 & Acceptable \\
NFI & $>0.9$ & 0.960 & Acceptable \\
CFI & $>0.9$ & 0.990 & Acceptable \\
PNFI & $>0.5$ & 0.643 & Acceptable \\
RMR & $<0.05$ & 0.047 & Acceptable \\
\hline
\end{tabular}


Table 3. Cont.

\begin{tabular}{ccc}
\hline & $\leq 0.05$ (close fit) & \\
$0.05-0.08$ (fair fit) & 0.030 & Fair fit \\
RMSEA & $0.08-0.10$ (mediocre fit) & \\
\multicolumn{2}{c}{$>0.10$ (poor fit) } & \\
\hline Note: GFI: goodness-of-fit index; AGFI: adjusted goodness-of-fit index; NFI: normalized fit index; PNFI: parsimo- \\
nious normed fit index; CFI: comparative fit index; RMR: root mean square residual; RMSEA: root mean square
\end{tabular}
error of approximation.

\section{Discussion}

The proposed model was evaluated by running SEM with the maximum likelihood estimation method. The findings indicated that our proposed model has a satisfactory predictive ability in outcome variables. The path analysis results and verification of the hypotheses are shown in Figure 2 and Table 4.

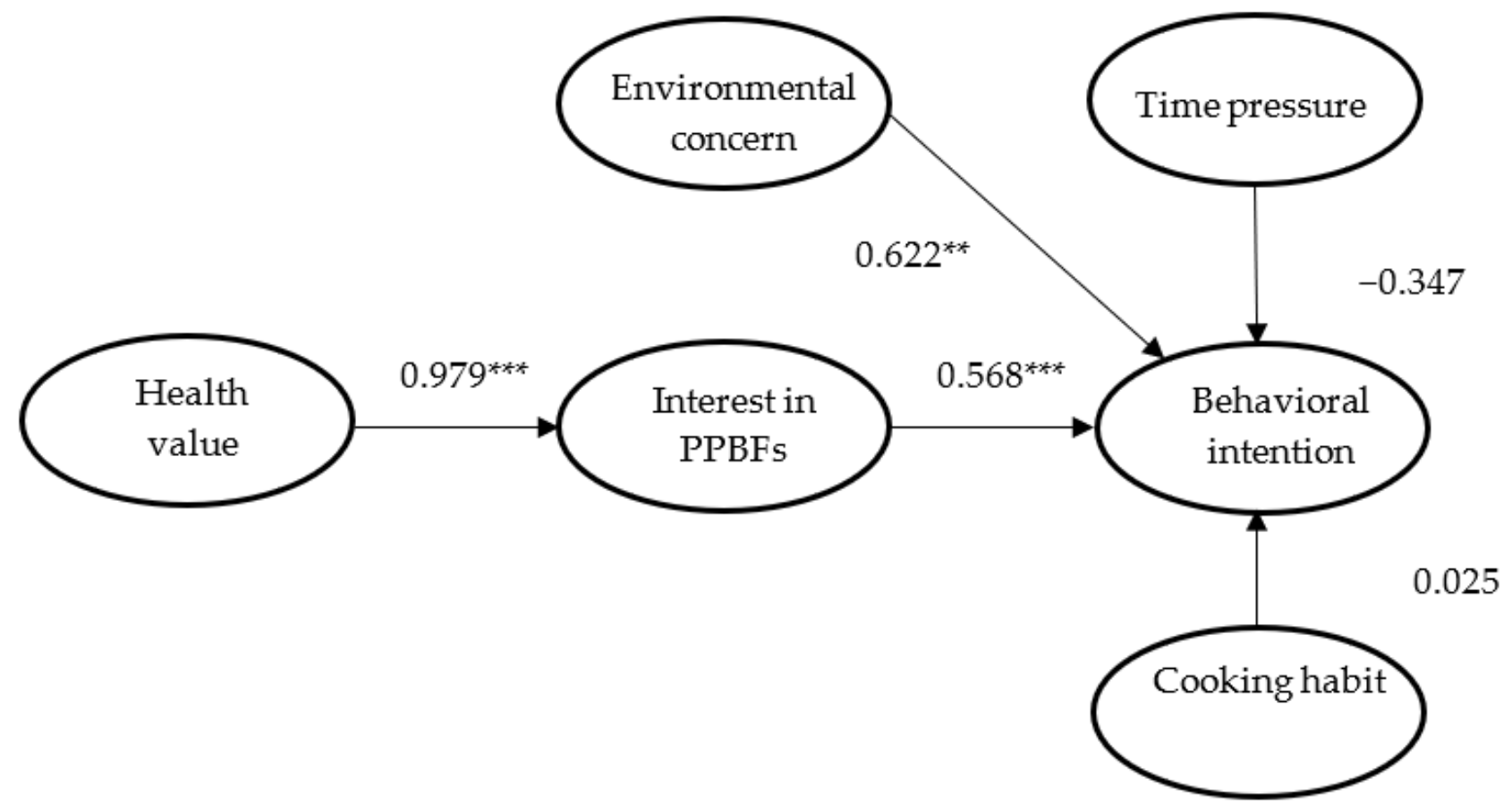

Figure 2. Paths within the hypothesis model. Note: ${ }^{* *} p<0.001 ;{ }^{* *} p<0.05$; solid lines denote established hypotheses.

Table 4. Summary of test results of research hypotheses.

\begin{tabular}{|c|c|c|c|}
\hline Research Hypothesis & Parameter Estimation & $t$-Value & Test Result \\
\hline H1: The health value will positively affect consumers' interest in PPBFs & $0.979 * * *$ & 100.42 & Valid \\
\hline $\begin{array}{c}\text { H2: Consumers' interest in PPBFs will positively affect their } \\
\text { behavioral intention }\end{array}$ & $0.568^{* * *}$ & 10.37 & Valid \\
\hline $\begin{array}{c}\text { H3: Consumers' environmental concern for PPBFs will positively affect their } \\
\text { behavioral intention }\end{array}$ & $0.622 * *$ & 2.90 & Valid \\
\hline $\begin{array}{c}\mathrm{H} 4: \text { Consumers' time pressure related to PPBFs will positively affect their } \\
\text { behavioral intention }\end{array}$ & -0.347 & -1.60 & Invalid \\
\hline $\begin{array}{c}\text { H5: Consumers' cooking habit related to PPBFs will negatively affect their } \\
\text { behavioral intention }\end{array}$ & 0.025 & 0.299 & Invalid \\
\hline
\end{tabular}

Note: ${ }^{* * *} p<0.001 ; * * p<0.05$.

The empirical results are in line with $\mathrm{H} 1$ of this study " $\mathrm{H} 1:$ The health value will positively affect consumers' interest in PPBFs $(\beta=0.979, p<0.001)$ "; therefore, this study holds that this hypothesis is valid. According to the results, consumers pay attention to 
their own health, and will generate interest in nutritious PPBFs based on their own health value. According to the empirical study by Jun, Kang, and Arendt [24], health value will positively affect consumers' healthy behaviors and attitude toward healthy products; thus, H1 stands.

The empirical results are in line with $\mathrm{H} 2$ of this study " $\mathrm{H} 2$ : Consumers' interest in PPBFs will positively affect their behavioral intention $(\beta=0.568, p<0.001)^{\prime \prime}$; therefore, this study holds that this hypothesis is valid. The research results indicate that the higher the consumers' interest in PPBFs, the more likely they will choose to buy PPBFs. According to the empirical study by Tudoran, Scholderer, and Brunsø [30], the more the consumers value health, the more likely they will choose healthy foods; thus, $\mathrm{H} 2$ stands.

The empirical results are in line with $\mathrm{H} 3$ of this study "H3: Consumers' environmental concern for PPBFs will positively affect their behavioral intention $(\beta=0.622, p<0.01)$ "; therefore, this study holds that this hypothesis is valid. In other words, the more the consumers value environmental concern, the deeper the impact on their green purchase behaviors. This finding is in line with the study by Pienaar, Lew, and Wallmo [46], which believes that consumers' environmental concern will influence their purchase behaviors; thus, H3 stands.

The empirical results are not in line with $\mathrm{H} 4$ of this study "H4: Consumers' time pressure related to PPBFs will positively affect their behavioral intention $(\beta=-0.347, p>0.01)^{\prime \prime}$; therefore, this study holds that this hypothesis is invalid. According to the research results, consumers' own time pressure is not the main factor influencing their purchase of PPBFs, which is inconsistent with the study by DeVoe and Pfeffer [55], which suggests with the increase in time pressure, consumers will believe their own time is more valuable and choose to buy instant foods; thus, H4 does not stand.

The empirical results are not in line with $\mathrm{H} 5$ of this study " $\mathrm{H} 5$ : Consumers' cooking habit related to PPBFs will negatively affect their behavioral intention $(\beta=0.025, p>0.01)$ "; therefore, this study holds that this hypothesis is invalid. The results indicate that the cooking habits of individuals and families will not impact consumers' purchase intention of PPBFs, which is inconsistent with the study findings of Contini et al. [19], which suggests individuals and families that are less likely to cook will seek more convenient dieting method; thus, H5 does not stand.

This study conducts empirical research on the causal relationship between constructs and research hypotheses, and it finds that $\mathrm{H} 1, \mathrm{H} 2$, and $\mathrm{H} 3$ are valid, whereas $\mathrm{H} 4$ and $\mathrm{H} 5$ are not. The research results indicate that consumers' health value will positively affect their interest in PPBFs, verifying the study by Jun, Kang, and Arendt [24], which holds that health value will positively affect consumers' healthy behaviors and attitude toward healthy products, thereby supporting H1. The higher the consumers' interest in PPBFs, the more likely they will purchase PPBFs, verifying the study by Tudoran, Scholderer, and Brunsø [30], which holds that the more consumers value health, the more likely they will choose healthy foods, thereby supporting H2. Moreover, the greater environmental concern consumers hold, the deeper the impact on their green purchasing behaviors. This is in line with the study by Pienaar, Lew, and Wallmo [46], which suggests that consumers' environmental concern will influence their product purchase behaviors, thereby supporting $\mathrm{H} 3$.

According to the research results, consumers' own time pressure is not a main factor influencing their purchase of PPBFs, and this finding is not in line with the study by DeVoe and Pfeffer [55], which suggests that with the increase in time pressure, consumers will consider their own time more valuable and choose to buy instant foods; thus, H4 is not supported. The research results verify that the cooking habits of individuals and families will not impact consumers' purchase intention of PPBFs, which is inconsistent with the study by Contini et al. [19], which suggests that individuals and families that are less likely to cook will seek more convenient dieting methods; thus, H5 is not supported. In summary, among the five research hypotheses developed in this study, H1, H2, and H3 are valid, whereas $\mathrm{H} 4$ and $\mathrm{H} 5$ are not. 
The test results for cause-effect model parameter estimation and research hypotheses are summarized in Table 4.

\section{Conclusions}

\subsection{Managerial Implications}

In light of the results, this study identifies the following conclusions:

1. The results show that consumers have established the concept regarding environmental friendliness brought by PPBFs, thus confirming that plant-based foods capable of providing convenience combined with healthy qualities can highlight that consumers' environmental concern will encourage them to purchase green products, and it is an important reference factor for evaluating food quality [36].

2. The time pressure does not influence their final behavioral intention. In fact, it is contrary to what we had hypothesized. The results show that consumers will not consider time pressure when consuming food; rather, they will feel time pressure when using food [6].

3. The cooking habits of individuals or families do not influence their final behavioral intention. The results indicate that consumers choose to consume PPBF irrelevant to the cooking habits of individuals or families of the local residents who lived in Taichung city, Taiwan. This finding is coherent with the literature; cooking habit will vary owing to cultural differences, climate conditions, and growth environments [57].

\subsection{Limitations of the Study and Scope for Future Research}

This study strives for correction in implementation and design, but it still has the following limitations.

\subsubsection{With Regards to the Research Tool}

This study adopted the investigation research method, used a self-developed "Questionnaire on Behavioral Intention toward PPBFs" as the research tool, and the data collected were mainly the data obtained from questionnaire survey. It was believed that respondents would fill out the questionnaire in an objective way and the questionnaire would serve as the basis for data analysis. However, the questionnaires used in this study are a self-descriptive research tool. As variable measurement is completed through respondents' cognitive responses, data collected via questionnaire survey may be subject to the impact of respondents' subjective judgment and frankness in answering the questions.

\subsubsection{With Regards to Research Samples}

This study uses consumers who have consumed PPBFs as respondents, making it impossible to conduct a comprehensive exploration of the thoughts of other Taiwanese consumers who have not consumed PPBFs. This is a limitation of sampling.

\subsubsection{With Regards to Research Methodology}

Considering that there were only a handful of previous studies on this topic, this study mainly adopted the empirical research method, seeking to have an integrated understanding from a broad perspective. It can also be regarded as an exploratory and introductory examination, aimed to inspire more in-depth research on related topics. This kind of largescale data collection has empirical advantages; however, it may not be able to conduct an in-depth research on related topics. On this account, it is believed that subsequent studies can fill this gap. Furthermore, this study is a cross-sectional study, so the data collected cannot verify the long-term effect of this research model.

Topics related to environmental ecology and sustainable development are valued by today's consumers. However, PPBFs are not widely accepted by consumers, despite the fact that newspapers and magazines have coverage about PPBFs, and that PPBFs are relatively friendly to environmental ecology and sustainable development just like organic foods and green products. Therefore, this study suggests that future research should take into 
account the cultural factors and individual psycho-social characteristics of the respondents (e.g., religious practice such as Buddhism), and examine their perception and opinion about PPBFs. Furthermore, this study also suggests that other variables (e.g., novel foods, health awareness) are to be included and examined to determine whether they are factors influencing the purchase intention of consumers, so as to make the research framework more complete.

Author Contributions: All authors contributed to the completion of this article. Formal analysis; investigation; data curation and writing — original draft preparation, M.-Y.C.; investigation, data curation, writing—review and editing, L.-J.H.; writing—original draft preparation, writing—review and editing, H.-S.C. All authors have read and agreed to the published version of the manuscript.

Funding: This research received no external funding.

Institutional Review Board Statement: Not applicable.

Informed Consent Statement: Not applicable.

Data Availability Statement: Not applicable.

Acknowledgments: We would like to express our sincere appreciation to all the experts who have taken the time to review this article and provide valuable comments.

Conflicts of Interest: The authors declare no conflict of interest.

\section{References}

1. Jones, C.S. Taking Up Space? How Customers React to Health Information and Health Icons on Restaurant Menus. J. Food Serv. Bus. Res. 2009, 12, 344-363. [CrossRef]

2. Yach, D.; Stuckler, D.; Brownell, K.D. Epidemiologic and economic consequences of the global epidemics of obesity and dia-betes. Nat. Med. 2006, 12, 62-66. [CrossRef] [PubMed]

3. Global Wellness Institute (GWI). Global Wellness Economy Monitor. 2018. Available online: https://globalwellnessinstitute.org/ press-room/pressreleases/wellness-now-a-4-2-trillion-global-industry/ (accessed on 12 January 2021).

4. YouGov and Whole Foods Market. Millennials' Food Choices are Driven by Quality and They're Willing to Pay More for It. Available online: https:/ / today.yougov.com/topics/food/articles-reports/2019/09/09/millennials-food-choices-are-drivenquality (accessed on 12 January 2021).

5. Hanson, N.; Yun, W. Should "big food" companies introduce healthier options? The effect of new product announcements on shareholder value. Mark. Lett. 2018, 29, 1-12. [CrossRef]

6. Contini, C.; Boncinelli, F.; Marone, E.; Scozzafava, G.; Casini, L. Drivers of plant-based convenience foods consumption: Re-sults of a multicomponent extension of the theory of planned behaviour. Food Qual. Prefer. 2020, 84, 103931. [CrossRef]

7. Ricci, E.C.; Banterle, A.; Stranieri, S. Trust to Go Green: An Exploration of Consumer Intentions for Eco-friendly Convenience Food. Ecol. Econ. 2018, 148, 54-65. [CrossRef]

8. $\quad$ Rokeach, M. The Nature of Human Values; Free Press: New York, NY, USA, 1973.

9. Honkanen, P.; Verplanken, B.; Olsen, S.O. Ethical values and motives driving organic food choice. J. Consum. Behav. 2006, 5, 420-430. [CrossRef]

10. Ajzen, I. The theory of planned behavior. Organ. Behav. Hum. Decis. Process. 1991, 50, 179-211. [CrossRef]

11. Teng, Y.-M.; Wu, K.-S.; Huang, D.-M. The Influence of Green Restaurant Decision Formation Using the VAB Model: The Effect of Environmental Concerns upon Intent to Visit. Sustainability 2014, 6, 8736-8755. [CrossRef]

12. Tudoran, A.; Olsen, S.O.; Dopico, D.C. The effect of health benefit information on consumers health value, attitudes and intentions. Appetite 2009, 52, 568-579. [CrossRef] [PubMed]

13. Cheung, M.F.Y.; To, W.M. An extended model of value-attitude-behavior to explain Chinese consumers' green purchase be-havior. J. Retail. Con. Serv. 2019, 50, 145-153. [CrossRef]

14. Kim, M.J.; Hall, C.M.; Kim, D.K. Predicting environmentally friendly eating out behavior by value-attitude-behavior theory: Does being vegetarian reduce food waste? J. Sustain. Tour. 2020, 28, 797-815. [CrossRef]

15. Zhang, L.; Chen, L.; Wu, Z.; Zhang, S.; Song, H. Investigating Young Consumers' Purchasing Intention of Green Housing in China. Sustainability 2018, 10, 1044. [CrossRef]

16. Li, C.; Li, C.; Yu, H.; Cheng, Y.; Xie, Y.; Yao, W.; Guo, Y.; Qian, H. Chemical food contaminants during food processing: Sources and control. Crit. Rev. Food Sci. Nutr. 2021, 61, 1545-1555. [CrossRef] [PubMed]

17. Shin, Y.H.; Moon, H.; Jung, S.E.; Severt, K. The effect of environmental values and attitudes on consumer willingness to pay more for organic menus: A value-attitude-behavior approach. J. Hosp. Tour. Manag. 2017, 33, 113-121. [CrossRef]

18. Jabs, J.; Devine, C.M. Time scarcity and food choices: An overview. Appetite 2006, 47, 196-204. [CrossRef] [PubMed] 
19. Contini, C.; Boncinelli, F.; Gerini, F.; Scozzafava, G.; Casini, L. Investigating the role of personal and context-related factors in convenience foods consumption. Appetite 2018, 126, 26-35. [CrossRef] [PubMed]

20. Mills, S.; White, M.; Brown, H.; Wrieden, W.; Kwasnicka, D.; Halligan, J.; Robalino, S.; Adams, J. Health and social determi-nants and outcomes of home cooking: A systematic review of observational studies. Appetite 2017, 111, 116-134. [CrossRef] [PubMed]

21. Caraher, M.; Dixon, P.; Lang, T.; Carr-Hill, R. The state of cooking in England: The relationship of cooking skills to food choice. Br. Food J. 1999, 101, 590-609. [CrossRef]

22. Hartmann, C.; Dohle, S.; Siegrist, M. Importance of cooking skills for balanced food choices. Appetite 2013, 65, 125-131. [CrossRef]

23. Tromp, D.M.; Brouha, X.D.R.; Hordijk, G.J.; Winnubst, J.A.M.; Gebhardt, W.A.; Van Der Doef, M.P.; De Leeuw, J.R.J. Medical care-seeking and health-risk behavior in patients with head and neck cancer: The role of health value, control beliefs and psychological distress. Health Educ. Res. 2005, 20, 665-675. [CrossRef]

24. Jun, J.; Kang, J.; Arendt, S.W. The effects of health value on healthful food selection intention at restaurants: Considering the role of attitudes toward taste and healthfulness of healthful foods. Int. J. Hosp. Manag. 2014, 42, 85-91. [CrossRef]

25. Olsen, S.O. Understanding the relationship between age and seafood consumption: The mediating role of attitude, health involvement and convenience. Food Qual. Prefer. 2003, 14, 199-209. [CrossRef]

26. Choe, J.Y.; Kim, S. Effects of tourists' local food consumption value on attitude, food destination image, and behavioral intention. Int. J. Hosp. Manag. 2018, 71, 1-10. [CrossRef]

27. Moisander, J. Motivational complexity of green consumerism. Int. J. Consum. Stud. 2007, 31, 404-409. [CrossRef]

28. Blackwell, R.D.; Miniard, P.W.; Engel, J.F. Consumer Behavior 9th; South-Western Thomas Learning: Mason, OH, USA, 2001.

29. Anderson, R.E.; Srinivasan, S.S. E-satisfaction and e-loyalty: A contingency framework. Psychol. Mark. 2003, 20, 123-138. [CrossRef]

30. Tudoran, A.A.; Scholderer, J.; Brunsø, K. Regulatory focus, self-efficacy and outcome expectations as drivers of motivation to consume healthy food products. Appetite 2012, 59, 243-251. [CrossRef] [PubMed]

31. Kock, F.; Josiassen, A.; Assaf, A.G. Advancing destination image: The destination content model. Ann. Tour. Res. 2016, 61, 28-44. [CrossRef]

32. Zandstra, E.; de Graaf, C.; Van Staveren, W. Influence of health and taste attitudes on consumption of low- and high-fat foods. Food Qual. Prefer. 2001, 12, 75-82. [CrossRef]

33. Høy, B.; Wagner, L.; Hall, E.O. Self-care as a health resource of elders: An integrative review of the concept. Scand. J. Caring Sci. 2007, 21, 456-466. [CrossRef] [PubMed]

34. Roininen, K. Evaluation of Food Choice Behavior: Development and Validation of Health and Taste Attitude Scales; University of Helsinki: Helsinki, Finland, 2001.

35. De Groot, J.; Steg, L. General Beliefs and the Theory of Planned Behavior: The Role of Environmental Concerns in the TPB. J. Appl. Soc. Psychol. 2007, 37, 1817-1836. [CrossRef]

36. Wandel, M.; Bugge, A. Environmental concern in consumer evaluation of food quality. Food Qual. Prefer. 1997, 8, 19-26. [CrossRef]

37. Hansla, A.; Gamble, A.; Juliusson, A.; Gärling, T. The relationships between awareness of consequences, environmental concern, and value orientations. J. Environ. Psychol. 2008, 28, 1-9. [CrossRef]

38. Helm, S.V.; Pollitt, A.; Barnett, M.A.; Curran, M.A.; Craig, Z.R. Differentiating environmental concern in the context of psychological adaption to climate change. Glob. Environ. Chang. 2018, 48, 158-167. [CrossRef]

39. Skogen, K.; Helland, H.; Kaltenborn, B. Concern about climate change, biodiversity loss, habitat degradation and landscape change: Embedded in different packages of environmental concern? J. Nat. Conserv. 2018, 44, 12-20. [CrossRef]

40. Tran, Y.; Yamamoto, T.; Sato, H. On the reciprocal relationship between environmental concerns and car use: Evidence from Nagoya, Japan. Asian Transp. Stud. 2020, 6, 100002. [CrossRef]

41. Freire, O.; Quevedo-Silva, F.; Frederico, E.; Vils, L.; Braga Junior, S.S.B. Effective scale for consumers' environmental con-cerns: A competing scales study between NEP and ECCB. J. Clean. Prod. 2021, 304, 126801. [CrossRef]

42. Lee, K.H.; Hwang, K.H.; Kim, M.; Cho, M. 3D printed food attributes and their roles within the value-attitude-behavior model: Moderating effects of food neophobia and food technology neophobia. J. Hosp. Tour. Manag. 2021, 48, 46-54. [CrossRef]

43. Nilsson, A.; Hansla, A.; Heiling, J.M.; Bergstad, C.J.; Martinsson, J. Public acceptability towards environmental policy measures: Value-matching appeals. Environ. Sci. Policy 2016, 61, 176-184. [CrossRef]

44. D'Amico, M.; Di Vita, G.; Monaco, L. Exploring environmental consciousness and consumer preferences for organic wines without sulfites. J. Clean. Prod. 2016, 120, 64-71. [CrossRef]

45. Arısal, I.; Atalar, T. The Exploring Relationships between Environmental Concern, Collectivism and Ecological Purchase Intention. Procedia-Soc. Behav. Sci. 2016, 235, 514-521. [CrossRef]

46. Pienaar, E.F.; Lew, D.K.; Wallmo, K. The importance of survey content: Testing for the context dependency of the New Eco-logical Paradigm Scale. Soc. Sci. Res. 2015, 51, 338-349. [CrossRef] [PubMed]

47. Ahituv, N.; Igbaria, M.; Sella, A.V. The effects of time pressure and completeness of information on decision making. J. Manag. Inf. Syst. 1998, 15, 153-172. [CrossRef]

48. Perlow, R.; Moore, D.D.W.; Kyle, R.; Killen, T. Convergent Evidence among Content-Specific Versions of Working Memory Tests. Educ. Psychol. Meas. 1999, 59, 866-877. [CrossRef]

49. De Paola, M.; Gioia, F. Who performs better under time pressure? Results from afield experiment. J. Econ. Psychol. 2016, 53, 37-53. [CrossRef] 
50. Saqib, N.U.; Chan, E. Time pressure reverses risk preferences. Organ. Behav. Hum. Decis. Process. 2015, 130, 58-68. [CrossRef]

51. Kaplan, M.F.; Wanshula, L.T.; Zanna, M.P. Time Pressure and Information Integration in Social Judgment. In Time Pressure and Stress in Human Judgment and Decision Making; Springer: New York, NY, USA, 1993; pp. 255-267.

52. Dhar, R.; Nowlis, S.M. The Effect of Time Pressure on Consumer Choice Deferral. J. Consum. Res. 1999, 25, 369-384. [CrossRef]

53. Hamermesh, D.S.; Lee, J. Stressed Out on Four Continents: Time Crunch or Yuppie Kvetch? Rev. Econ. Stat. 2007, 89, 374-383. [CrossRef]

54. Etkin, J.; Evangelidis, I.; Aaker, J. Pressed for Time? Goal Conflict Shapes how Time is Perceived, Spent, and Valued. J. Mark. Res. 2015, 52, 394-406. [CrossRef]

55. DeVoe, S.E.; Pfeffer, J. Time is tight: How higher economic value of time increases feelings of time pressure. J. Appl. Psychol. 2011, 96, 665-676. [CrossRef] [PubMed]

56. Pettinger, C.; Holdsworth, M.; Gerber, M. Meal patterns and cooking practices in Southern France and Central England. Public Health Nutr. 2006, 9, 1020-1026. [CrossRef]

57. Zylberberg, D. Fuel Prices, Regional Diets and Cooking Habits in the English Industrial Revolution (1750-1830). Past Present 2015, 229, 91-122. [CrossRef]

58. Lang, M. Consumer acceptance of blending plant-based ingredients into traditional meat-based foods: Evidence from the meat-mushroom blend. Food Qual. Prefer. 2020, 79, 103758. [CrossRef]

59. Sheth, J.N.; Newman, B.I.; Gross, B.L. Why we buy what we buy: A theory of consumption values. J. Bus. Res. 1991, 22, 159-170. [CrossRef]

60. Jo, H.; Lee, S.; Choe, Y. Home Meal Replacement Market Segmentation: A Food-Related Life Style (No. 329-2016-12871). 2014. Available online: https:/ /ageconsearch.umn.edu/record/170253/ (accessed on 24 March 2021).

61. Fornell, C.; Larcker, D.F. Structural Equation Models with Unobservable Variables and Measurement Error: Algebra and Statistics. J. Mark. Res. 1981, 18, 382-388. [CrossRef]

62. Jöreskog, K.G.; Sörbom, D. LISREL 8: Structural Equation Modeling with the SIMPLIS Command Language; Scientific Software International: Lawrence Erlbaum Associates Inc.: Hillsdale, NJ, USA, 1993.

63. Bagozzi, R.P.; Yi, Y. On the evaluation of structural equation models. J. Acad. Mark. Sci. 1988, 16, 76-94. [CrossRef] 